\title{
O COMPARTILHAMENTO DE CAMA ENTRE MÃE E FILHO E O SEU IMPACTO NA CONTINUIDADE DO ALEITAMENTO MATERNO.
}

\author{
Letícia Silva Caires'; Graciete Oliveira Vieira ${ }^{2}$; Jannine Rios Santos Serra ${ }^{3}$ \\ 1. Bolsista PIBIC/CNPq, Graduando em Medicina, Universidade Estadual de Feira de Santana, e-mail: \\ leticiacaires04@hotmail.com \\ 2. Orientador, Departamento de Saúde, Universidade Estadual de Feira de Santana, e-mail: \\ gracieteovieira@gmail.com \\ 3. Participante do projeto e membro do NUPES, Departamento de Saúde, Universidade Estadual de Feira de Santana, \\ e-mail: janninerios@ hotmail.com
}

PALAVRAS-CHAVE: cama compartilhada, aleitamento materno, infância.

\section{INTRODUÇÃO}

O aleitamento materno (AM) é necessário para o bom crescimento físico e o desenvolvimento cognitivo da criança. Ele não só nutre, mas aumenta o vínculo mãefilho, promove defesa contra infecções e tem impacto positivo no desenvolvimento emocional (BRASIL, 2009a). O ato de amamentar e ser amamentado é muito prazeroso para a mãe e o filho, sendo uma oportunidade ímpar de troca de afeto e sentimentos de segurança (GIUGLIANE, 2010). O ser humano depende do organismo materno, para obter proteção, calor e alimento. O homem é geneticamente programado para ser amamentado e viver diariamente ao lado da mãe (GIUGLIANE, 2010).

A recomendação mundial é o aleitamento materno exclusivo (AME) por 6 meses e complementado até os 2 anos ou mais (BRASIL, 2009a). No entanto, o desmame precoce é elevado. A Organização Mundial da Saúde definiu metas globais de incentivo ao AM, entre elas aumentar as taxas de AME em 50\% até o ano de 2025 (IBFAN, 2012). Para atingir este objetivo, é necessário buscar fatores modificáveis que favoreçam a amamentação (BRASIL, 2009a), dentre esses encontra-se o compartilhamento de cama.

Estudos tem chamado a atenção que a cama compartilhada entre mãe e filho está associada ao prolongamento da amamentação (MITCHEL, 2004; HUSSAIN, 2015), principalmente em países ocidentais (BALL, 2016), pois as mães podem duplicar o número de mamadas à noite, o que aumenta os benefícios nutricionais para criança (HUSSAIN, 2015). Mesmo pouco estudada no Brasil, a prática de cama compartilhada é muito utilizada em diversas culturas e quase onipresentes em todos os primatas (GETTLER, 2011).

Pesquisas ainda são necessárias para embasar a recomendação da cama compartilhada entre mãe e filho, bem como sua adoção pelos principais órgãos da pediatria; mesmo diante da possibilidade do aumento de prevalência do AM (BLAIR, 2008). Neste sentido, é preciso realizar novos estudos para averiguar os benefícios da cama compartilhada, sobretudo no prolongamento do AM.

O objetivo principal do estudo é averiguar a associação entre cama compartilhada por mãe e filho e a continuidade do AM. Os objetivos específicos foram:

- Realizar uma revisão bibliográfica sobre a cama compartilhada e seus benefícios na continuidade do AM.

- Estimar a prevalência do AM das crianças menores de dois anos de idade da cidade de Feira de Santana, mediante o uso de cama compartilhada. 


\section{METODOLOGIA}

Para atender aos objetivos do atual plano de trabalho, foi realizado inicialmente uma revisão da literatura sobre o compartilhamento de cama entre mãe e filho e sua relação com o AM, mediante a busca de publicações nas bases de dados Medical Literature Analysis and Retrieval System Online/Pubmed, Literaturas LatinoAmericanas e do Caribe em Ciências da Saúde e Sciense Direct. Após a busca, foram selecionados 22 artigos que constituiu a base literária da discussão dos resultados do atual plano de trabalho, bem como serão utilizados no artigo, que será elaborado "Associação entre compartilhamento de cama e a continuidade do aleitamento materno", e terá como objetivo averiguar o compartilhamento de cama e outros fatores associados a continuidade do AM aos dois anos de idade, na cidade de Feira de Santana - Bahia.

Dados do artigo - Foi utilizado o banco de dados de uma coorte de nascidos vivos, mediante a autorização de sua coordenadora $\operatorname{Prof}^{\mathrm{a}} \operatorname{Dr}^{\mathrm{a}}$ Graciete Oliveira Vieira. A coorte foi composta por 1344 mães que foram acompanhadas por um período de 24 meses, sendo realizada visitas mensais nos primeiros 6 meses, após este período as visitas foram feitas aos 9, 12, 18 e 24 meses. As mães responderam a um questionário sobre as características maternas e infantis, aplicado sob a forma de entrevista direta, por um pesquisador previamente treinado. $\mathrm{O}$ banco de dados foi digitado no aplicativo Statistical Product and Service Solutions (SPSS).

Análise- A análise dos dados consistiu em duas etapas. Na primeira, foi realizado a análise descritiva das características maternas e infantis que será apresentada no atual plano de trabalho. Na segunda etapa, será realizada análise hierarquizada das características socioeconômicas e demográficas, do pré-natal, do parto e pós-parto, do recém-nascido, das mulheres e do lactente, que incluirá o compartilhamento de cama (Figura 1).

\begin{tabular}{|c|c|c|c|}
\hline$\underline{\text { Nível distal }}$ & $\frac{\frac{\text { Nível }}{\text { intermediário }}}{\underline{\text { distal }}}$ & $\frac{\frac{\text { Nível }}{\text { intermediário }}}{\text { proximal }}$ & Nível proximal \\
\hline $\begin{array}{c}\text { Características } \\
\text { socioeconômicas e } \\
\text { demográficas } \\
\text { - Cor da pele materna } \\
\text { - Idade materna na } \\
\text { época do parto } \\
\text { - Escolaridade materna } \\
\text { - Paridade } \\
\text { - Renda familiar }\end{array}$ & $\begin{array}{c}\text { Características do } \\
\text { pré-natal } \\
\text { - Ter assistido } \\
\text { palestras sobre } \\
\text { amamentação no pré- } \\
\text { natal } \\
\text { - Fez uso de tabaco na } \\
\text { gestação } \\
\text { - Realizado pré-natal } \\
\text { em serviço público } \\
\text { - Experiência prévia } \\
\text { com a amamentação }\end{array}$ & $\begin{array}{c}\text { Características do } \\
\text { parto e pós-parto } \\
\text { - Tipo de parto } \\
\text { - Parto em serviço } \\
\text { público } \\
\text { - Amamentação na } \\
\text { primeira hora de vida } \\
\text { - Alojamento conjunto } \\
\text { no hospital } \\
\text { - Orientação sobre } \\
\text { amamentação na } \\
\text { maternidade } \\
\text { - Expectativa materna } \\
\text { de amamentar por } 12 \\
\text { meses ou mais } \\
\text { Características do } \\
\text { recém-nascido } \\
\text { - Peso de nascimento } \\
\text { - Sexo na criança }\end{array}$ & $\begin{array}{c}\text { Características das } \\
\text { mulheres } \\
\text { - Trabalho materno fora do lar } \\
\text { na época da interrupção da } \\
\text { amamentação } \\
\text { - Trabalho materno com } \\
\text { carteira assinada } \\
\text { - Companheiro acha a } \\
\text { amamentação importante } \\
\text { - Coabitação com o pai da } \\
\text { criança } \\
\text { Características do lactente } \\
\text { - Uso de chupeta no momento } \\
\text { da interrupção da } \\
\text { amamentação } \\
\text { - Dormir na cama da mãe na } \\
\text { época da interrupção da } \\
\text { amamentação } \\
\text { - Aleitamento materno em } \\
\text { livre demanda no primeiro }\end{array}$ \\
\hline
\end{tabular}




\begin{tabular}{|l|l|c|}
\hline & & mês \\
& & $\begin{array}{c}\text { - Aleitamento materno } \\
\text { exclusivo no quarto mês } \\
\text { - Criança come dormindo aos } \\
24 \text { meses }\end{array}$ \\
\hline
\end{tabular}

Figura 1. Análise multivariada em níveis hierárquicos.

\section{RESULTADOS}

Encontramos as seguintes prevalências do AM: $48 \%$ na primeira hora de vida e $21 \%$ eram amamentadas exclusivamente no $4^{\circ}$ mês. A grande maioria das crianças eram amamentadas em livre demanda no primeiro mês de vida (95,8\%). As taxas encontradas estão aquém da recomendação de AME por 6 meses, bem como do prolongamento do aleitamento até os 2 anos de idade ou mais. No entanto, os dados globais também apresentam resultados abaixo das recomendações, pois somente $37 \%$ das crianças menores de seis meses são amamentadas exclusivamente (IBFAN, 2012). No Brasil, os dados de 2008 mostram uma prevalência de AME foi de 41\%, embora na região Nordeste seja de 37\%, uma das piores taxas brasileiras (BRASIL, 2009b).

Dentre as crianças avaliadas, 20,8\% mamavam aos 24 meses de idade. Esta duração do AM superam os relatados para o Brasil, na análise de tendência secular da amamentação com base em sete pesquisas nacionais realizadas entre 1975 a 2008 que observou o aumento da prática do AM de 2,5 (1974) para 7,3 (1996), 9,9 (1999), 11,9 (2006) e 11,3 meses (2008), quando avaliadas crianças menores de 12 meses (VENÂNCIO, 2013).

Notamos que, $77,8 \%$ das crianças dormiam na cama dos pais na época da interrupção da amamentação. Esta prática proporciona vínculo afetivo entre mãe e filho, melhor sono para o bebê (HUSSAIN, 2015). Dados mundiais sobre prevalência do compartilhamento de cama, informam que em países como América, Europa, Ásia e Oceania, a prevalência varie de 2 a $88 \%$. Nos EUA, essa rotina foi relatada em 12,8\% da população. No Brasil, apesar de dados escassos, observou-se que $46 \%$ dos bebês dormem na cama dos pais, no final do primeiro ano, em Pelotas no Rio Grande do Sul (ISSLER, 2010).

Outro estudo demostrou um fator positivo na associação entre o compartilhamento de cama e continuidade do AM, porém questiona a temporalidade entre os eventos (HUSSAIN, 2015). Ball (2016) conduziu um estudo com acompanhamento com 870 mães no período de 26 semanas, onde a partilha de cama foi dividida em "nunca compartilhou", "partilha intermitente" e "frequentemente compartilha". Foi encontrado uma associação positiva entre as mães que frequentemente compartilhavam a cama e o AM aos 6 meses.

Revisão sistemática evidencia que o compartilhamento de cama entre mães e filho favorece maior tempo de amamentação do que naquelas dormem em local separado. Porém, ela deixa claro o déficit de certeza de que o compartilhamento de cama tenha influência sobre a continuidade do aleitamento, já que existe a hipótese de que mães com maior intenção de amamentar escolhem ter as crianças por perto para facilitar a mamada (BJORNDAL, 2005).

\section{CONSIDERAÇÕES FINAIS}

Estudos mostram tendência positiva da prática do co-leito na duração do AM. No entanto, novos estudos devem ser realizados para se averiguar a influência dessa prática na duração do aleitamento materno, bem como os benefícios e a segurança desta 
na saúde infantil; uma vez que o compartilhamento de cama é um fator modificável e pode ser uma opção para o estimular a amamentação e evitar o desmame precoce.

\section{REFERÊNCIAS}

BALL, H.L; HOWEL, D; BRYANT, A; et al. Bed-sharing by breastfeeding mothers: who bed-shares and what is the relationship with breastfeeding duration? Acta paeditr., v. 105, p. 628-34, 2016.

BJORNDAL, A; RAGNHILD, A.; JENS, G; et al. Bed sharing, pacifier, breastfeeding and cot-death - is there a connection?. Oslo: Norwegian knowledge center for the health services, n. 5, p. 1-82, 2005.

BLAIR, P.S. Putting co-sleeping into perspective. Jornal de Pediatria, Rio de Janeiro, v. 84, n. 2, p. 99-101, 2008.

BRASIL. Ministério da Saúde. Departamento de Atenção Básica. Saúde da criança: nutrição infantil: aleitamento materno e alimentação complementar. Caderno de atenção básica, n, 23. Editora MS, p. 112, 2009a.

BRASIL. Ministério da saúde. Departamento de ações programáticas e estratégicas. II pesquisa de prevalência de aleitamento materno nas capitais brasileiras e distrito federal. Brasília: Editora do Ministério da Saúde, 108 p: il. 2009b.

FATHERSTON, C.M; LEACH, J.S. Analysis of the ethical issues in the breastfeeding and bedsharing debate. Breastfeeding Review, v. 20, n. 3, 2012.

GETTLER, L.T; MCKENNA J.J. Evoluationary perspectives on motherinfant sleep proximity and breastfeeding in a laboratory setting. American Journal of Physical Anthropology, Evanston, v. 144, n. 3, p. 454-62, 2011.

GIUGLIANE, E.R.J. Tópicos básicos em aleitamento materno. In: LOPEZ, F.A (Org); DIOCLÉCIO, C.J. Tratado de Pediatria: Sociedade Brasileira de Pediatria. 2. ed. Barueri, SP: Manole, 2010. p. 327-38.

HUSSAIN, S; LOWELL, G.S; ROEHLER, D.R; et al. You can have your breastmilk and safe sleep too: a preliminar analysis of infant safe sleep data in a Midwestern home visiting program. Injury epidemiology, v. 5, n. 1, p. 3-9, 2018.

IBFAN - International baby food action network. Entendendo o passado planejando o futuro: comemorando os 10 anos da estratégia global para a alimentação em lactentes e crianças da primeira infância da OMS/UNICEF. 2012. Disponível em: 〈http://www.ibfan.org.br/smam/pdf/doc-755.pdf>.

ISSLER, R.M.S; GIUGLIANI, E.R.J; MAROSTICA, P.J.C; et al. Coleito no primeiro semestre de vida: prevalência e fatores associados. Caderno de Saúde Pública, Rio de Janeiro, v. 36, n. 5, p. 942-948, 2010.

MITCHELL, E.A; HUTCHISON, B.L; THOMPSON, J; et al. Exploratory study of bed-sharing and maternal-infant bonding. Journal of paediatrics and child health, New Zealand, v. 51, p. 820-825, 2014.

SANTOS, I.S; MOTA, D.M; MATIJASEVICH, A; et al. Bed-sharing at 3 months and breast-feeding at 1 year in southern Brazil. Jounal of pediatrics, Pelotas, v. 155, n. 4, 2009.

VENÂNCIO, S.I; SALDIVA, S.R.D.M; MONTEIRO, C.A. Tendência secular da amamentação no Brasil. Rev Saúde Publ., v. 47, n. 6, p. 1205-8. 2013.

WENNERGREN, G. Why it is important to present all the available facts about bed sharing and breastfeeding. Acta Paediatrica, Sweden, v. 105, p. 22, 2016. 